\title{
Reducing the Excess Burden of Subsidizing the Stork: Joint Taxation, Individual Taxation, and Family Tax Splitting
}

\author{
VOLKER MEIER \\ MATTHIAS WREDE
}

CESIFO WORKING PAPER No. 2470

CATEgORY 1: Public FinANCE

NOVEMBER 2008

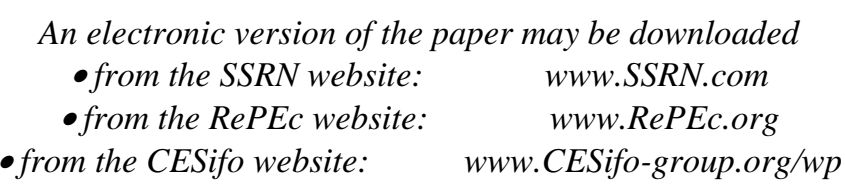




\title{
Reducing the Excess Burden of Subsidizing the Stork: Joint Taxation, Individual Taxation, and Family Tax Splitting
}

\begin{abstract}
Analyzing a homogenous household setting with endogenous fertility and endogenous labor supply, we demonstrate that moving from joint taxation to individual taxation and adapting child benefits so as to keep fertility constant entails a Pareto improvement. The change is associated with an increase in labor supply and consumption and a reduction of the marginal income tax, while the child benefit may move in either direction. Similarly, a move from joint taxation to some scheme of family tax splitting increases labor supply and welfare.
\end{abstract}

JEL Code: H21, H24, H31, J18, J22.

Keywords: income taxation, fertility, splitting, labor supply.

Volker Meier

Ifo Institute for Economic Research and CESifo at the University of Munich

Poschingerstrasse 5

81679 Munich

Germany

meier@ifo.de
Matthias Wrede

University of Marburg

Faculty of Business Administration and

Economics

Am Plan 2

35032 Marburg

Germany

wrede@wiwi.uni-marburg.de

November 7, 2008 


\section{Introduction}

The taxation of couples and families has undergone substantial changes in the last decades. Among the major economies, joint taxation is still in place in the US and in Germany. At the same time, there is an obvious international trend to move from joint taxation to individual taxation with or without additional child benefits. Joint taxation is perceived as an obstacle against increasing labor supply of wives because marginal tax rates are higher than under individual taxation. In a progressive income tax scheme with rising marginal tax rates, joint taxation yields tax savings when income of the spouses is distributed in an uneven fashion. At the same time, the marginal tax rate related to the smaller income will be higher than under individual taxation to generate a fixed tax revenue per capita. Moreover, joint taxation is not very precise as a means to encourage fertility, as all possible tax savings are independent of the number of children. Nevertheless, when mothers have to reduce labor supply at least temporarily, joint taxation reduces the opportunity cost associated with foregone labor income.

In this paper we argue that joint taxation is not efficient. A Pareto improvement can be achieved by moving to individual taxation, accompanied by appropriate child benefits. The argument runs as follows. Joint taxation distorts the decisions of individuals stronger than individual taxation. When moving from individual taxation to joint taxation, substitution effects drive labor supply down and fertility up. Replacing joint taxation with individual taxation to arrive at the same budget deficit per capita will be associated with an increased labor supply and a smaller marginal income tax. Applying the Pareto criterion requires that we compare allocations where all individuals exist in either allocation. The idea therefore is to adapt a child benefit when moving from joint taxation to individual taxation so as to keep fertility constant. Since the distortion of labor supply is reduced, the reform toward individual taxation raises welfare. Applying the same method to a move from joint taxation to some scheme of family tax splitting also yields a Pareto 
improvement via an increasing labor supply.

In principle, it does not make sense to introduce a child benefit when income taxation already distorts the fertility decision upwards. This may be different in an environment with positive externalities of having children. For example, positive externalities of fertility exist if a pay-as-you-go scheme is present where the return to social security contributions rises with a higher number of individuals in the following generation (see Cigno et al., 2003).

The literature on the taxation of couples has mainly treated fertility as exogenous. Kleven et al. (2006) do not even consider children or household production explicitly. In an optimum taxation model where the couple determines the labor supply of both the primary and the secondary earner, it turns out that the optimal marginal tax of one individual decreases in the income of the other individual. This property of negative jointness is not satisfied in real-world income tax schemes, neither with individual nor with joint taxation. If the primary earner is extremely rich, the marginal tax on secondary income converges to zero. Apps and Rees (2007) introduce household production into the model of Boskin and Sheshinski (1983). They argue that both joint taxation and individual taxation are inferior to selective taxation where female labor income is taxed at lower marginal rates than the wages of males. This message can clearly be traced back to the principle of Ramsey taxation stating that taxes should be lowest where labor supply elasticities are particularly high. While joint taxation eliminates possible distortions of the technical rates of substitution between household and market production (Piggott and Whalley, 1996), joint taxation never constitutes the optimal policy because Ramsey taxation requires to distort all activities (Apps and Rees, 1999). It cannot even be excluded that the optimum tax regime requires a smaller marginal tax on the income of the primary earner (Kleven and Kreiner, 2003).

The empirical literature literature on reforms aiming at changing the taxation of couples seems inconclusive. Feldstein and Feenberg (1996), considering a possible move in the US from joint taxation to reduced tax rates for 
married women, find strong labor supply increases of these women that contribute substantially to financing the tax cut. Steiner and Wrohlich (2008) analyze moves from joint income taxation to different specifications of family tax splitting. As their estimates of labor supply elasiticities are small, such reforms have mainly distributional impacts, where all reforms yield gains for the rich and losses for the poor. Beblo et al. (2004) arrive at similar conclusions when considering a move from the German joint taxation scheme to the French system of family tax splitting, stressing that substantial labor supply reactions can be expected only for rich women with more than two children.

Another strand of the literature is concerned with the impacts of alternative policy instruments on fertility and female labor supply. Apps and Rees (2004) show that introducing a subsidy for purchased child care financed by a reduction of family allowances will increase both fertility and female labor supply. Furthermore, increasing the male tax rate and reducing the female tax rate so as to keep total tax revenue constant always increases labor supply, while the impact on fertility depends both on the weight of fertility in the utility function and on the elasticity of substitiution between different types of child care. Although the price of a child increases due to a higher opportunity cost, fertility may increase due to an income effect if the female labor supply reaction is strong. Cigno $(1983,1986)$ argues that the government would like to accompany child subsidies by taxes on adult consumption to avoid a smaller investment in child quality when fertility increases.

In other settings a distributional objective of the government determines the tax policy. Cremer et al. (2003) obtain optimal marginal tax rates decreasing in the number of children in an optimal taxation problem where the government can observe the number of children and total income, but not working hours. Balestrino (2001) considers a rich set of instruments with a wage tax, a tax (or subsidy) on the number of children and indirect taxes referring to consumption goods of children and adults. With identical wages across households, all goods, including children, will be taxed according to a Ramsey rule to achieve symmetric distortions of decisions. Imposing the 
usual structure of preference for the quantity and quality of children, distributional considerations lead the government to subsidize the number of children and to tax child consumption in order to redistribute toward poor families. However, if demand for consuming child-specific commodities decreases with a higher wage rate of the mother, the size of the family will be taxed while child-specific commodites are subsidized (Balestrino et al., 2002, Cigno and Pettini, 2002).

Finally, Fraser (2001) considers parents who reduce fertility as a response to income risk. Employing child benefits instead of lump-sum benefits can then bring about a Pareto improvement by encouraging an increase in fertility. While he does not address the choice of the tax regime, this line of reasoning indicates that joint taxation provides some additional insurance agains losses from unemployment and may thus increase fertility.

The remainder of the paper is organized as follows. Section 2 introduces our model. In Section 3, we analyze the consequences of moving from joint to individual taxation with adapting policy instruments so as to keep both fertility and the government budget balanced. Section 4 deals with a similar move from joint taxation to family tax splitting, and the final Section 5 discusses our main findings.

\section{The model}

Consider a homogenous population of couples where the utility function $U(c, n, l)$ is strictly increasing and strictly concave in its arguments consumption $c$, the number of children $n$ and leisure of the wife $l$. We neglect the integer constraint on the number of children. There are three uses of time, namely work, leisure and time spent with children. Total time is normalized to unity, and raising one child requires $k$ units of time and $p$ units of the consumption good. The child benefit is equal to $\beta$. Each household has an exogenous income $y_{0}$ that is earned by the husband. This assumption reflects the finding of the empirical literature that labor supply elasticities of 
husbands in their prime age are generally very close to zero. The wife's wage rate is $w$, and the income tax $T$ depends on the two earned incomes. Hence, the household's budget equation is

$$
c=y_{0}+y_{1}-T\left(y_{0}, y_{1}\right)-n(p-\beta)
$$

where $y_{1}=w(1-l-n k)$ is the wife's income. For the sake of concreteness, we assume that the wife is the secondary earner: $y_{0} \geq w$. The government provides $g$ units of a public or private good per household, where the level is fixed. This good does not enter the utility function explicitly. The government uses a progressive tax function $\phi(y ; t)$, with $\phi_{1}>0, \phi_{2}>0, \phi_{11} \geq 0$, and $\phi_{12}>0$, where $y$ denotes income of the taxable unit, $t$ is a tax parameter, and the the index $i$ denotes the derivative with respect to the $i$ th argument. The marginal tax rate is increasing weakly. However, in order to make the analysis meaningful, we assume that the marginal tax rate increases somewhere in the relevant range, that is, $\phi_{1}\left(\left(y_{0}+y_{1}\right) / 2\right)>\phi_{1}\left(y_{1}\right)$ at any $y_{1}<y_{0}$.

The total tax that has to be paid by a couple with individual incomes $y_{0}$ and $y_{1}$ is

$$
T\left(y_{0}, y_{1}\right)=\alpha\left[\phi\left(y_{0} ; t\right)+\phi\left(y_{1} ; t\right)\right]+(1-\alpha) 2 \phi\left(\frac{y_{0}+y_{1}}{2} ; t\right) .
$$

This specification contains the pure joint taxation scheme as the boundary case $\alpha=0$ and the pure individual taxation scheme at the other boundary $\alpha=1$. The budget equation of the government is

$$
T-\beta n-g=0,
$$

with $g$ denoting public expenditure per household.

After inserting its budget constraint, the household chooses the number of children $n$ and leisure $l$ so as to maximize utility

$$
V(n, l):=U(c, n, l) \text { s.t. }(1)
$$


It should be noted that we do not necessarily arrive at a unique solution to the optimization problem of the household, since the budget set is not convex. Due to the progressive tax schedule, increasing the demand for leisure by one unit repeatedly is associated with a decreasing loss in consumption. If uniqueness and an interior solution are ensured, the first-order conditions are

$$
\begin{aligned}
U_{n}-U_{c} \pi & =0 \\
U_{l}-U_{c} \psi & =0
\end{aligned}
$$

where

$$
\psi:=w\left(1-\frac{\partial T}{\partial y_{1}}\right)>0
$$

is the marginal net price of leisure,

$$
\pi:=p-\beta+k \psi
$$

is the marginal net price of a child, and

$$
\frac{\partial T}{\partial y_{1}}=\alpha \phi_{1}\left(y_{1} ; t\right)+(1-\alpha) \phi_{1}\left(\frac{y_{0}+y_{1}}{2} ; t\right)>0
$$

is the marginal tax rate of the household. Having an additional child increases utility directly by $U_{n}$. At the same time, it reduces consumption according to the direct $\operatorname{cost} p$ net of the child allowance $\beta$, the gross opportunity cost $k w$ and the possible change of the income tax $-w k \partial T / \partial y_{1}$. Increasing the demand for leisure by one unit directly raises utility by $U_{l}$, but reduces consumption according to the loss in net income given by $w\left(1-\partial T / \partial y_{1}\right)$.

We only consider situations with a positive net price of a child because otherwise a solution to the optimization problem does not exist. Further, we impose the regularity assumptions $U_{c c} \psi-U_{c l}<0$ and $U_{l l}-U_{c l} \psi<0$, that is, increasing labor supply and using the additional net wage income for consumption decreases the marginal utility of consumption and increases the marginal utility of leisure. Obviously, these regularity conditions are fulfilled for additive-separable utility functions. We also assume that the sufficient second-order conditions are satisfied, that is, $V_{n n}<0, V_{l l}<0$ and $\Delta_{1}:=V_{n n} V_{l l}-V_{n l}^{2}>0$. 


\section{Tax policy analysis}

The first-order conditions implicitly define the number of children $n$ and leisure $l$ as functions of the three policy parameters, the tax structure parameter $\alpha$, the child benefit $\beta$, and the tax rate parameter $t$ :

$$
\begin{aligned}
n & =n(\beta, t ; \alpha), \\
l & =l(\beta, t ; \alpha) .
\end{aligned}
$$

We proceed by analyzing a change in the tax structure parameter $\alpha$ when the child benefit $\beta$ and the tax rate parameter $t$ are altered so as to stabilize the number of children per household, $n$, and the public budget. In any symmetric equilibrium, each mother has the same number of children and each household pays the same amount of taxes net of child benefits. Changing the tax structure parameter $\alpha$ affects child benefits as well as marginal and average tax rates. Hence, we determine $d \beta / d \alpha$ and $d t / d \alpha$ from

$$
\begin{aligned}
n(\beta, t ; \alpha)-\bar{n} & =0 \\
T(\beta, t ; \alpha)-\beta n(\beta, t ; \alpha)-g & =0
\end{aligned}
$$

where we lightly abuse notation by using again the symbol $T$.

Let the dynamic evolution of the child benefit and the tax rate parameter be governed by the following system of differential equations:

$$
\begin{aligned}
\dot{\beta} & =f_{1}(n(\beta, t ; \alpha)-\bar{n}) \\
\dot{t} & =f_{2}(T(\beta, t ; \alpha)-g-\beta n(\beta, t ; \alpha)),
\end{aligned}
$$

with $f_{1}(0)=f_{2}(0)=0, f_{1}^{\prime}<0$ and $f_{2}^{\prime}<0$. Hence, the child benefit is increased if fertility falls short of the target level $\bar{n}$, and vice versa. Similarly, the tax rate parameter is raised when the government runs a budget deficit, while tax rates will fall if we have a budget surplus. An equilibrium of this dynamic system is locally asymptotically stable only if at the equilibrium

point the three conditions $\partial \dot{\beta} / \partial \beta \leq 0, \partial \dot{t} / \partial t \leq 0$, and $(\partial \dot{\beta} / \partial \beta)(\partial \dot{t} / \partial t)-$ 


$$
\begin{aligned}
(\partial \dot{\beta} / \partial t)(\partial \dot{t} / \partial \beta) & =f_{1}^{\prime} f_{2}^{\prime} \Delta_{2} \geq 0 \text { are met, with } \\
\Delta_{2} & =\frac{\partial n}{\partial \beta}\left(\frac{\partial T}{\partial l} \frac{\partial l}{\partial t}+\frac{\partial T}{\partial t}\right)-\frac{\partial n}{\partial t}\left(\frac{\partial T}{\partial l} \frac{\partial l}{\partial \beta}-n\right) .
\end{aligned}
$$

For simplicity, we assume in the following that the sufficient stability condition is satisfied, that is, we have strict inequalities in each case.

Proposition 1 summarizes the impacts of increasing the share of individual taxation on the household demand structure and the policy parameters of the government.

Proposition 1 Any increase of the share of individual taxation $\alpha$ with additional changes in the child benefit $\beta$ and the tax rate parameter $t$ so as to keep fertility constant and the government budget balanced reduces demand for leisure and increases both labor supply and demand for consumption goods. The child benefit parameter $\beta$ can move in either direction. The marginal tax rate of the household at the new equilibrium will be lower.

Proof. See Appendix A.

The result can be interpreted as follows. In a first step, shifting the tax scheme toward individual taxation reduces the marginal tax rate. Therefore, both the price of leisure and the price of a child go up through the higher opportunity cost. At the same time, the tax rate parameter is adapted in such a way that the total net tax the household pays stays constant if all households behave symmetrically. As demand changes are therefore governed by substitution effects only, we expect a rising labor supply and a falling demand for children. The increase in labor supply, however, is associated with a move to a higher marginal tax rate, which reduces the price of a child. Moreover, as the additional wage income is spent on consumption, the marginal utility of consumption falls, which reduces utility losses from costs associated with increasing fertility. Simulation examples in Appendix B show that the sum of the two indirect effects that increase fertility may both be weaker or stronger than the depressing effect of the direct price increase. 
In a second step, the child benefit is raised or reduced in order to reach again the initial number of children. At given demand for leisure, labor supply moves in the opposite direction. Both this labor supply reaction and the changed expenditure on child benefits requires adapting the tax rate parameter in the direction of the change in the child benefit. Again, there is no redistribution across households in a symmetric equilibrium. The difference between taxes paid and child benefits received is unchanged when all households react in an identical fashion. If the price of a child is reduced due to a rising child benefit, the initial price of a child is already achieved before the marginal tax rate reaches its initial level. The new equilibrium is associated with a smaller marginal tax rate. Due to the absence of redistribution across households, the labor supply decision will be driven by a substitution effect according to the new price of leisure. As this price lies lower than in the initial situation, labor supply and consumption will increase, while leisure falls.

Since the marginal rate of substitution between consumption and leisure does not coincide with the marginal rate of transformation, moving the relative price closer to the marginal rate of transformation carries the potential of a welfare increase. This suspicion is confirmed by Proposition 2 .

Proposition 2 Any increase of the share of individual taxation $\alpha$ with additional changes in the child benefit $\beta$ and the tax rate parameter $t$ so as to keep fertility constant and the government budget balanced increases welfare.

Proof. From Proposition 1, we know that $d l / d \alpha<0$. The stabilization policy concerning fertility and net tax revenue implies that in a symmetric equilibrium

$$
c+w l=\text { constant }
$$

holds true. Therefore, welfare changes according to

$$
d U=U_{c}(c, l, \bar{n}) d c+U_{l}(c, l, \bar{n}) d l=\left[U_{l}(c, l, \bar{n})-w U_{c}(c, l, \bar{n}) w\right] d l
$$

if the number of children remains constant. Using the first-order condition 
governing the demand for leisure (5), we arrive at

$$
\frac{d U}{d \alpha}=-U_{c}(c, l, \bar{n}) w \frac{\partial T}{\partial y_{1}} \frac{d l}{d \alpha}>0 .
$$

Proposition 2 is easily understood. The policy experiment consists again in simultaneously increasing the share of individual taxation, and varying both the child benefit and the marginal tax rate parameter so as to keep the government budget balanced and to induce unchanged fertility. Proposition 1 has established that this policy reduces the demand for leisure while keeping the net tax constant. Since the demand for leisure was distorted upward in the initial allocation, its reduction implies a welfare gain.

\section{$4 \quad$ Family splitting}

Family splitting can be perceived as a goal-directed instrument to support families and to increase birth rates. Our model can easily be used to analyze the impact of a move from simple joint taxation towards family splitting. In order to do so, we redefine some basic variables and functions. First of all, the tax of the household is written as

$$
T\left(y_{0}, y_{1}\right)=(2+\gamma n) \phi\left(\frac{y_{0}+y_{1}}{2+\gamma n} ; t\right),
$$

where $\gamma \in[0,1]$ is the children splitting factor. An increase in $\gamma$ represents a transition from couple-oriented income splitting towards family splitting. Since with $\phi_{11}=0$ a change in $\gamma$ has no direct impact on the marginal tax rate, $\phi_{11}>0$ is assumed in this section. The direct effect of an increase in $\gamma$ on the tax burden is given by

$$
\frac{\partial T}{\partial \gamma}=\frac{n\left(y_{0}+y_{1}\right)}{2+\gamma n}\left[\frac{T}{y_{0}+y_{1}}-\frac{\partial T}{\partial y_{1}}\right]<0,
$$

where

$$
\frac{\partial T}{\partial y_{1}}=\phi_{1}>0
$$


is the marginal tax rate of the household. Since under a progressive tax schedule the marginal tax rate exceeds the average tax rate, an increase in $\gamma$ reduces the tax burden of the family at a given tax parameter $t$.

Furthermore, a move towards family splitting also reduces the marginal tax rate at given $t$, since

$$
\frac{\partial^{2} T}{\partial y_{1} \partial \gamma}=-\frac{n\left(y_{0}+y_{1}\right)}{(2+\gamma n)^{2}} \phi_{11}<0 .
$$

With family splitting, the net price of a child is

$$
\pi=p-\beta+k \psi+\frac{\gamma}{2+\gamma n}\left[T\left(y_{0}, y_{1}\right)-\left(y_{0}+y_{1}\right) \frac{\partial T}{\partial y_{1}}\right]
$$

If $\gamma>0$, the net price of a child under a family splitting scheme falls short of $p-\beta+k \psi$, because according to the tax formula additional children reduce the family's tax burden.

Comparing the analysis to the previous section, there are only two changes. The definition of the net price of a child is modified, and the individual taxation factor $\alpha$ is replaced by the family splitting factor $\gamma$. The optimality conditions on the household level are still given by (4) and (5), and the equilibrium conditions for the government are analogous to (11) and (12). However, since the net price of a child has changed, the expressions describing the impact of a change in the parameter $\gamma$ on leisure and the marginal tax rate look slightly different. Nevertheless, family splitting has a likewise beneficial impact on leisure and welfare, as summarized by Proposition 3 .

Proposition 3 Any increase of the children splitting factor $\gamma$ with additional changes in the child benefit $\beta$ and the tax rate parameter $t$ so as to keep fertility constant and the government budget balanced reduces demand for leisure and the marginal tax rate of the household, and increases both labor supply and demand for consumption goods. Welfare at the new equilibrium will be higher.

Proof. See Appendix C. 
Family splitting reduces the marginal tax rate just as individual taxation does. At the same time, the direct impact on the price of a child is ambiguous. First, the reduction of the marginal income tax increases the price of a child via a higher opprtunity cost. Second, raising the children splitting factor increases the tax saving factor $\gamma /(2+\gamma n)$, which reduces the price of a child. Third, the impact on the difference between the marginal tax rate and the average tax rate, $\partial T / \partial y_{1}-T\left(y_{0}, y_{1}\right) /\left(y_{0}+y_{1}\right)$, is ambiguous. It will be negative, and thus increase the price of a child if the degree of progessivity, as measured by $\phi_{11}$, is not too large.

Hence, before adaptation of $t$ and $\beta$, labor supply tends to increase, while fertility may move in either direction. At given fertility, a rising labor supply increases the marginal income tax, which reduces the opportunity cost of a child. Spending the additional income on consumption reduces the marginal utility of consumption and therefore also the utility loss associated with a given price of a child. Finally, as the difference between marginal tax and average tax rate increases, the price of a child is reduced through a higher tax saving.

While it would be necessary to increase the tax parameter $t$ to balance the budget at unchanged behavior, the rising labor supply works in the opposite direction. It turns out that labor supply is also higher in the new equlibrium, and the overall effect on the marginal tax rate is negative. As in the case of moving toward individual taxation, increasing the family splitting factor raises welfare because it reduces the distortion on labor supply.

\section{Concluding discussion}

Our analysis has demonstrated that joint taxation is inferior to both individual taxation and family tax splitting in a homogenous household environment for a fairly general framework of income tax schedules and utility functions. Among all tax schemes being considered, joint taxation is associated with 
lowest labor supply and the highest marginal tax rate on the earnings of the wife.

An obvious question is how the case in favor of replacing joint taxation by individual taxation can be made in an environment with heterogeneous households. The task is far from easy because changes in the structure of taxation will be associated with distributional consequences. Therefore, achieving a Pareto improvement sometimes require additional measures to correct such distributional impacts.

The first possibility is that households are differentiated according to the exogenous income, being interpreted as wage income of the primary earner. Richer households face a higher marginal tax under joint taxation for any given labor supply of the secondary earner. As substitution and income effects work in the same direction, we may expect that fertility is higher and labor supply is lower if the exogenous income $y_{0}$ is higher. Moving from joint taxation to individual taxation tends to harm rich and help poor households at unchanged behavior. Neutralizing the distributional impact may therefore imply to use tax allowances rather than uniform child benefits.

A second scenario arises when considering households with differences in the wife's wage rate. When changing this wage rate, income and substitution effects work in opposite directions. Hence, there is no theoretical prediction in which direction labor supply and fertility will react. The empirically relevant case seems to consist in dominating substitution effects, where wives with a higher wage rate work more and have less children. Moving from joint taxation to individual taxation at unchanged behavior will then redistribute from the poor to the rich. This is a consequence of the fact that joint taxation reduces the tax load particularly strong when the two incomes are quite uneven. At the same time, again at unchanged behavior, a uniform child benefit would redistribute income from rich to poor families.

Finally, we may consider households that are differentiated with respect to the number of children. Couples may have decided against births or simply cannot have children. We suppose that households without children typically 
display both a higher demand for pure leisure and a higher labor supply. While a move toward individual taxation tends to harm families due to a more uneven distribution of individual incomes, the distributional consequences of a possibly increasing child benefit work in the opposite direction.

Moving from joint taxation to a family tax splitting scheme has analogous consequences. The change is particularly beneficial for richer households with either a higher primary or secondary income. In both cases the redistributional impact will typically be partially compensated by an increase in the tax parameter and a cut of tax allowances. People without children are harmed by moving to family tax splitting, but may benefit from a cut of child benefits.

Summing up, the argument against joint taxation will, with some modifications, presumably carry over to several generalizations with differentiated households. At the same time, it is clear that a Pareto improving transition from joint taxation to either an individualized system or family tax splitting becomes impossible in environments with differences in several dimensions if asymmetric information prevails across all dimensions.

An interesting question left open for future research lies in the comparison of individual taxation and family tax splitting at the maximum child factor. It is not obvious whether these two schemes can also be ranked by employing our methodology. Individual taxation tends to offer the strongest incentive for labor supply of the secondary earner by imposing a heavy tax load on the wage of the primary earner. On the other hand, considering a convex combination of both schemes and increasing the share of individual taxation can increase rather than decrease the marginal income tax before adapting the tax parameter and the child benefit. Such a surprising reaction may occur if both labor supply and fertility are high. Hence, though our simulations currently suggest the superiority of the individualized scheme, it cannot be excluded that the ranking of the two tax regimes ultimately depends on the specification of the utility function. 


\section{Appendix}

\section{A: Proof of Proposition 1}

Notice that

$$
\begin{aligned}
& \frac{d \beta}{d \alpha}=-\frac{1}{\Delta_{2}}\left[-\frac{\partial n}{\partial t}\left(\frac{\partial T}{\partial l} \frac{\partial l}{\partial \alpha}+\frac{\partial T}{\partial \alpha}\right)+\frac{\partial n}{\partial \alpha}\left(\frac{\partial T}{\partial l} \frac{\partial l}{\partial t}+\frac{\partial T}{\partial t}\right)\right] \\
& \frac{d t}{d \alpha}=-\frac{1}{\Delta_{2}}\left[\frac{\partial n}{\partial \beta}\left(\frac{\partial T}{\partial l} \frac{\partial l}{\partial \alpha}+\frac{\partial T}{\partial \alpha}\right)-\frac{\partial n}{\partial \alpha}\left(\frac{\partial T}{\partial l} \frac{\partial l}{\partial \beta}-n\right)\right] .
\end{aligned}
$$

The change in the demand for leisure is determined by

$$
\frac{d l}{d \alpha}=\frac{\partial l}{\partial \alpha}+\frac{\partial l}{\partial t} \frac{d t}{d \alpha}+\frac{\partial l}{\partial \beta} \frac{d \beta}{d \alpha} .
$$

It can be shown that

$$
\begin{aligned}
\frac{d l}{d \alpha} \Delta_{2}= & \frac{\partial l}{\partial \alpha}\left[\frac{\partial n}{\partial \beta} \frac{\partial T}{\partial t}+n \frac{\partial n}{\partial t}\right] \\
& -\frac{\partial l}{\partial t}\left[\frac{\partial n}{\partial \beta} \frac{\partial T}{\partial \alpha}+n \frac{\partial n}{\partial \alpha}\right]+\frac{\partial l}{\partial \beta}\left[\frac{\partial n}{\partial t} \frac{\partial T}{\partial \alpha}-\frac{\partial n}{\partial \alpha} \frac{\partial T}{\partial t}\right] .
\end{aligned}
$$


Using the second derivatives of $V$ with respect to the endogenous variables and the parameters

$$
\begin{aligned}
a_{11} & =U_{n n}-2 U_{c n} \pi-U_{c} \frac{\partial \pi}{\partial y_{1}} \frac{\partial y_{1}}{\partial n}+U_{c c} \pi^{2}=V_{n n}<0, \\
a_{12} & =U_{n l}-U_{c l} \pi-U_{c n} \psi+U_{c c} \pi \psi-U_{c} \frac{\partial \pi}{\partial y_{1}} \frac{\partial y_{1}}{\partial l}=V_{n l}=a_{21}, \\
a_{22} & =U_{l l}-2 U_{c l} \psi-U_{c} \frac{\partial \psi}{\partial y_{1}} \frac{\partial y_{1}}{\partial l}+U_{c c} \psi^{2}=V_{l l}<0, \\
b_{11} & =U_{c}-U_{c c} \pi n+U_{n c} n=V_{n \beta}, \\
b_{12} & =U_{c} w k \frac{\partial^{2} T}{\partial y_{1} \partial \alpha}+\left[U_{c c} \pi-U_{n c}\right] \frac{\partial T}{\partial \alpha}=V_{n \alpha}, \\
b_{13} & =U_{c} w k \frac{\partial^{2} T}{\partial y_{1} \partial t}+\left[U_{c c} \pi-U_{n c}\right] \frac{\partial T}{\partial t}=V_{n t}, \\
b_{21} & =n\left[U_{c l}-U_{c c} \psi\right]=V_{l \beta}, \\
b_{22} & =U_{c} w \frac{\partial^{2} T}{\partial y_{1} \partial \alpha}+\left[U_{c c} \psi-U_{c l}\right] \frac{\partial T}{\partial \alpha}=V_{l \alpha}, \\
b_{23} & =U_{c} w \frac{\partial^{2} T}{\partial y_{1} \partial t}+\left[U_{c c} \psi-U_{c l}\right] \frac{\partial T}{\partial t}=V_{l t},
\end{aligned}
$$

and evaluating the derivatives of demand for children and leisure with respect to the parameters $\alpha, \beta$, and $t$ yields, after rearranging,

$$
\begin{aligned}
\frac{d l}{d \alpha} \Delta_{1}^{2} \Delta_{2}= & n\left[a_{11} a_{22}-a_{12} a_{21}\right]\left[b_{13} b_{22}-b_{12} b_{23}\right] \\
& +\frac{\partial T}{\partial t}\left[a_{11} a_{22}-a_{12} a_{21}\right]\left[b_{11} b_{22}-b_{21} b_{12}\right] \\
& +\frac{\partial T}{\partial \alpha}\left[a_{11} a_{22}-a_{12} a_{21}\right]\left[b_{21} b_{13}-b_{11} b_{23}\right]
\end{aligned}
$$

Inserting for the terms $b_{x y}$ finally shows that

$$
\frac{d l}{d \alpha} \Delta_{1} \Delta_{2}=U_{c}^{2} w\left[\frac{\partial T}{\partial t} \frac{\partial^{2} T}{\partial y_{1} \partial \alpha}-\frac{\partial T}{\partial \alpha} \frac{\partial^{2} T}{\partial y_{1} \partial t}\right]
$$

as all other terms cancel out. Since

$$
\frac{\partial T}{\partial t}>0, \quad \frac{\partial^{2} T}{\partial y_{1} \partial \alpha}<0, \quad \frac{\partial T}{\partial \alpha}>0, \quad \text { and } \quad \frac{\partial^{2} T}{\partial y_{1} \partial t}>0
$$


it follows that $d l / \alpha<0$. Recalling that the number of children is kept constant, labor supply moves in the opposite direction. Since the net tax stays constant, the increase in labor supply implies a rise in consumption.

The change of the equilibrium marginal income tax is determined by

$$
\frac{d\left(\partial T / \partial y_{1}\right)}{d \alpha}=\frac{\partial^{2} T}{\partial y_{1} \partial \alpha}+\frac{\partial^{2} T}{\partial y_{1} \partial t} \frac{d t}{d \alpha}+\frac{\partial^{2} T}{\partial y_{1} \partial l} \frac{d l}{d \alpha} .
$$

Calculating $d\left(\partial T / \partial y_{1}\right) / d \alpha$ shows that

$$
\begin{aligned}
\frac{d\left(\partial T / \partial y_{1}\right)}{d \alpha} \frac{\Delta_{1} \Delta_{2}}{U_{c}}= & {\left[\frac{\partial T}{\partial t} \frac{\partial^{2} T}{\partial y_{1} \partial \alpha}-\frac{\partial T}{\partial \alpha} \frac{\partial^{2} T}{\partial y_{1} \partial t}\right] } \\
& \cdot\left[\frac{\partial T}{\partial l}\left(U_{c c} \psi-U_{c l}\right)-a_{22}+\frac{\partial^{2} T}{\partial y_{1} \partial l} U_{c} w\right] \\
= & {\left[\frac{\partial T}{\partial t} \frac{\partial^{2} T}{\partial y_{1} \partial \alpha}-\frac{\partial T}{\partial \alpha} \frac{\partial^{2} T}{\partial y_{1} \partial t}\right] } \\
& \cdot\left[-U_{l l}+U_{c l} \psi+w\left[U_{c l}-U_{c c} \psi\right]\right]
\end{aligned}
$$

Given that $U_{c c} \psi-U_{c l}<0$ and $U_{l l}-U_{c l} \psi<0$, this suffices to establish $d\left(\partial T / \partial y_{1}\right) / d \alpha<0$.

\section{B: Ambiguous reaction of child benefit}

We consider the additively separable utility function $U=\delta_{c} \ln c+\delta_{n} \ln n+$ $\delta_{l} \ln l$, where $\delta_{c}=0.5, \delta_{n}=0.3$, and $\delta_{l}=0.2$. Let the tax function be quadratic, with the tax parameter $t$ entering multiplicatively:

$$
T=t\left[\frac{1-\alpha}{2}\left(y_{0}+y_{1}\right)^{2}+\alpha\left(y_{0}^{2}+y_{1}^{2}\right)\right] \text {. }
$$

The exogenous income of the primary earner is set to $y_{0}=2$, the wage rate of the secondary earner is $w=1.8$, the number of children is stabilized at $n=2$, and the net tax revenue is $g=0.5$.

In the first example, the direct cost of a child is set to $p=0.4$ and the time cost is $k=0.05$. Moving the tax structure parameter continuously from $\alpha=$ 0 to $\alpha=1$ reduces the child benefit monotonously from $\beta(\alpha=0)=0.0460$ 
to $\beta(\alpha=1)=0.0065$. The tax parameter $t$ declines from $t(\alpha=0)=0.1692$ to $t(\alpha=1)=0.1084$.

In the second example, the direct cost of a child is set to $p=0.2$ and the time cost is $k=0.2$. Moving the tax structure parameter continuously from $\alpha=0$ to $\alpha=1$ increases the child benefit monotonously from $\beta$ ( $\alpha=$ $0)=0.0164$ to $\beta(\alpha=1)=0.0669$. The tax parameter $t$ declines from $t(\alpha=0)=0.2407$ to $t(\alpha=1)=0.1524$.

\section{C: Proof of Proposition 3}

Proceeding as in the proof of Proposition 1, and using

$$
\begin{aligned}
V_{n n} & =U_{n n}-2 U_{c n} \pi-U_{c}\left[k \frac{\partial \psi}{\partial y_{1}} \frac{\partial y_{1}}{\partial n}+\frac{\gamma}{n} \frac{\partial^{2} T}{\partial \gamma \partial n}-\frac{\gamma}{n^{2}} \frac{\partial T}{\partial \gamma}\right]+U_{c c} \pi^{2}<0 \\
V_{n l} & =U_{n l}-U_{c l} \pi-U_{c n} \psi+U_{c c} \pi \psi-U_{c} \frac{\partial \pi}{\partial y_{1}} \frac{\partial y_{1}}{\partial l} \\
V_{l l} & =U_{l l}-2 U_{c l} \psi-U_{c} \frac{\partial \psi}{\partial y_{1}} \frac{\partial y_{1}}{\partial l}+U_{c c} \psi^{2}<0 \\
V_{n \beta} & =U_{c}-U_{c c} \pi n+U_{n c} n=V_{n \beta} \\
V_{n \gamma} & =U_{c}\left[w k \frac{\partial^{2} T}{\partial y_{1} \partial \gamma}-\frac{\gamma}{n} \frac{\partial^{2} T}{\partial \gamma^{2}}-\frac{1}{n} \frac{\partial T}{\partial \gamma}\right]+\left[U_{c c} \pi-U_{n c}\right] \frac{\partial T}{\partial \gamma} \\
V_{n t} & =U_{c}\left[w k \frac{\partial^{2} T}{\partial y_{1} \partial t}-\frac{\gamma}{n} \frac{\partial^{2} T}{\partial \gamma \partial t}\right]+\left[U_{c c} \pi-U_{n c}\right] \frac{\partial T}{\partial t} \\
V_{l \beta} & =n\left[U_{c l}-U_{c c} \psi\right] \\
V_{l \gamma} & =U_{c} w \frac{\partial^{2} T}{\partial y_{1} \partial \gamma}+\left[U_{c c} \psi-U_{c l}\right] \frac{\partial T}{\partial \gamma} \\
V_{l t} & =U_{c} w \frac{\partial^{2} T}{\partial y_{1} \partial t}+\left[U_{c c} \psi-U_{c l}\right] \frac{\partial T}{\partial t}
\end{aligned}
$$

the impact of a change in $\gamma$ on leisure can be calculated:

$$
\frac{d l}{d \gamma}=\frac{U_{c}^{2} w}{\Delta_{1} \Delta_{2}}\left[\frac{\partial T}{\partial t} \frac{\partial^{2} T}{\partial y_{1} \partial \gamma}+\gamma\left(\frac{\partial^{2} T}{\partial \gamma^{2}} \frac{\partial^{2} T}{\partial y_{1} \partial t}-\frac{\partial^{2} T}{\partial \gamma \partial t} \frac{\partial^{2} T}{\partial y_{1} \partial \gamma}\right)\right] .
$$


Inserting

$$
\begin{aligned}
\frac{\partial^{2} T}{\partial \gamma \partial t} & =\frac{n}{2+\gamma n} \frac{\partial T}{\partial t}-\frac{n\left(y_{0}+y_{1}\right)}{2+\gamma n} \frac{\partial^{2} T}{\partial y_{1} \partial t} \\
\frac{\partial^{2} T}{\partial \gamma^{2}} & =-\frac{n\left(y_{0}+y_{1}\right)}{2+\gamma n} \frac{\partial^{2} T}{\partial y_{1} \partial \gamma}
\end{aligned}
$$

yields

$$
\frac{d l}{d \gamma}=\frac{U_{c}^{2} w}{\Delta_{1} \Delta_{2}}\left[\frac{2}{2+\gamma n}\right] \frac{\partial T}{\partial t} \frac{\partial^{2} T}{\partial y_{1} \partial \gamma}<0 .
$$

Recalling that the number of children is kept constant, labor supply moves in the opposite direction. Since the net tax stays constant, the increase in labor supply implies a rise in consumption.

Tedious computations show that

$$
\begin{aligned}
\frac{d\left(\partial T / \partial y_{1}\right)}{d \gamma} \frac{\Delta_{1} \Delta_{2}}{U_{c}}= & {\left[\frac{\partial^{2} T}{\partial y_{1} \partial l} U_{c} w+\frac{\partial T}{\partial l}\left[U_{c c} \psi-U_{c l}\right]-V_{l l}\right] } \\
& \cdot\left[\frac{\partial T}{\partial t} \frac{\partial^{2} T}{\partial y_{1} \partial \gamma}+\gamma\left(\frac{\partial^{2} T}{\partial \gamma^{2}} \frac{\partial^{2} T}{\partial y_{1} \partial t}-\frac{\partial^{2} T}{\partial \gamma \partial t} \frac{\partial^{2} T}{\partial y_{1} \partial \gamma}\right)\right]
\end{aligned}
$$

which finally yields

$$
\frac{d\left(\partial T / \partial y_{1}\right)}{d \gamma}=-\frac{U_{l l}-U_{d l} \psi-w\left(U_{c l}-U_{c c} \psi\right)}{U_{c} w} \frac{d l}{d \gamma}<0 .
$$

Furthermore, $d U>0$ can be derived using the same reasoning as in the proof of Proposition 2. 


\section{References}

Apps, P. and Rees, R. (1999). Joint vs Individual Taxation in Models of Household Production. Journal of Political Economy 107, 178-190.

Apps, P. and Rees, R. (2004). Fertility, Taxation and Family Policy. Scandinavian Journal of Economics 106, 745-763.

Apps, P. and Rees, R. (2007). The Taxation of Couples. IZA Discussion Paper No. 2910. Bonn.

Balestrino, A. (2001). On the Optimal Fiscal Treatment of Family Size. Finanzarchiv 58, 140-157.

Balestrino, A., Cigno, A. and Pettini, A. (2002). Endogenous Fertility and the Design of Family Taxation. International Tax and Public Finance 9, 175-193.

Beblo, M., Beninger, D. and Laisney, F. (2004). Family Tax Splitting: A Microsimulation of Its Potential Labour Supply and Intra-household Welfare Effects in Germany. Applied Economics Quarterly 50, 233-250.

Boskin, M. and Sheshinski, E. (1983). The Optimal Tax Treatment of the Family. Journal of Public Economics 20, 281-297.

Cigno, A. (1986). Fertility and the Tax-benefit System: A Reconsideration of the Theory of Family Taxation. Economic Journal 96, 1035-1051.

Cigno, A. (1996). Cost of Children, Parental Decisions and Family Policy. Labour 10, 461-474.

Cigno, A. (2001). Comparative Advantage, Observability, and the Optimal Tax Treatment of Families with Children. International Tax and Public Finance 8, 451-466.

Cigno, A and Pettini, A. (2002). Taxing Family Size and Subsidizing ChildSpecific Commodities. Journal of Public Economics 84, 75-90. 
Cigno, A., A. Luporini and A. Pettini. (2003). Transfers to Families with Children as a Principal-Agent Problem. Journal of Public Economics $87,1165-1177$.

Cremer, H., Dellis, A. and Pestieau, P. (2003). Family Size and Optimal Income Taxation. Journal of Population Economics 6, 37-54.

Feldstein, M. and Feenberg, D.R. (1996). The Taxation of Two-Earner Families. In M. Feldstein and J. M. Poterba (eds) Empirical Foundations of Household Taxation. University of Chicago Press: Chicago, 39-76.

Fraser, C.D. (2001). Income Risk, the Tax Benefit System and the Demand for Children. Economica 68, 105-125.

Kleven, H. J., Kreiner, C. T. (2003). On the Optimality of Joint Taxation with Household Production. In: H. J. Kleven (ed.) Taxation, Time allocation, and Economic Efficiency. Copenhagen, pp. 1-22.

Kleven, H. J., Kreiner, C. T., Saez, E. (2006). The Optimal Income Taxation of Couples. NBER Working Paper No. 12685, Cambridge, MA.

Piggott, J. and Whalley, J. (1996). The Tax Unit and Household Production. Journal of Political Economy 104, 398-418.

Steiner, V. and Wrohlich, K. (2008). Fiscal Policy in Action: Introducing Family Tax Splitting in Germany: How would it Affect the Income Distribution, Work Incentives, and Household Welfare? Finanzarchiv $64,115-142$. 


\section{CESifo Working Paper Series}

for full list see www.cesifo-group.org/wp

(address: Poschingerstr. 5, 81679 Munich, Germany, office@cesifo.de)

2409 Alexander Kemnitz, Native Welfare Losses from High Skilled Immigration, September 2008

2410 Xavier Vives, Strategic Supply Function Competition with Private Information, September 2008

2411 Fabio Padovano and Roberto Ricciuti, The Political Competition-Economic Performance Puzzle: Evidence from the OECD Countries and the Italian Regions, September 2008

2412 Joan Costa-Font and Mireia Jofre-Bonet, Body Image and Food Disorders: Evidence from a Sample of European Women, September 2008

2413 Thorsten Upmann, Labour Unions - To Unite or to Separate?, October 2008

2414 Sascha O. Becker and Ludger Woessmann, Luther and the Girls: Religious Denomination and the Female Education Gap in $19^{\text {th }}$ Century Prussia, October 2008

2415 Florian Englmaier and Stephen Leider, Contractual and Organizational Structure with Reciprocal Agents, October 2008

2416 Vittorio Daniele and Ugo Marani, Organized Crime and Foreign Direct Investment: The Italian Case, October 2008

2417 Valentina Bosetti, Carlo Carraro, Alessandra Sgobbi and Massimo Tavoni, Modelling Economic Impacts of Alternative International Climate Policy Architectures. A Quantitative and Comparative Assessment of Architectures for Agreement, October 2008

2418 Paul De Grauwe, Animal Spirits and Monetary Policy, October 2008

2419 Guglielmo Maria Caporale, Christophe Rault, Robert Sova and Anamaria Sova, On the Bilateral Trade Effects of Free Trade Agreements between the EU-15 and the CEEC-4 Countries, October 2008

2420 Yin-Wong Cheung and Daniel Friedman, Speculative Attacks: A Laboratory Study in Continuous Time, October 2008

2421 Kamila Fialová and Ondřej Schneider, Labour Market Institutions and their Effect on Labour Market Performance in the New EU Member Countries, October 2008

2422 Alexander Ludwig and Michael Reiter, Sharing Demographic Risk - Who is Afraid of the Baby Bust?, October 2008 
2423 Doina Maria Radulescu and Michael Stimmelmayr, The Welfare Loss from Differential Taxation of Sectors in Germany, October 2008

2424 Nikolaus Wolf, Was Germany ever United? Evidence from Intra- and International Trade 1885 - 1933, October 2008

2425 Bruno S. Frey, David A. Savage and Benno Torgler, Noblesse Oblige? Determinants of Survival in a Life and Death Situation, October 2008

2426 Giovanni Facchini, Peri Silva and Gerald Willmann, The Customs Union Issue: Why do we Observe so few of them?, October 2008

2427 Wido Geis, Silke Uebelmesser and Martin Werding, Why go to France or Germany, if you could as well go to the UK or the US? Selective Features of Immigration to four major OECD Countries, October 2008

2428 Geeta Kingdon and Francis Teal, Teacher Unions, Teacher Pay and Student Performance in India: A Pupil Fixed Effects Approach, October 2008

2429 Andreas Haufler and Marco Runkel, Firms' Financial Choices and Thin Capitalization Rules under Corporate Tax Competition, October 2008

2430 Matz Dahlberg, Heléne Lundqvist and Eva Mörk, Intergovernmental Grants and Bureaucratic Power, October 2008

2431 Alfons J. Weichenrieder and Tina Klautke, Taxes and the Efficiency Costs of Capital Distortions, October 2008

2432 Andreas Knabe and Ronnie Schöb, Minimum Wage Incidence: The Case for Germany, October 2008

2433 Kurt R. Brekke and Odd Rune Straume, Pharmaceutical Patents: Incentives for R\&D or Marketing?, October 2008

2434 Scott Alan Carson, Geography, Insolation, and Institutional Change in $19^{\text {th }}$ Century African-American and White Stature in Southern States, October 2008

2435 Emilia Del Bono and Daniela Vuri, Job Mobility and the Gender Wage Gap in Italy, October 2008

2436 Marco Angrisani, Antonio Guarino, Steffen Huck and Nathan Larson, No-Trade in the Laboratory, October 2008

2437 Josse Delfgaauw and Robert Dur, Managerial Talent, Motivation, and Self-Selection into Public Management, October 2008

2438 Christian Bauer and Wolfgang Buchholz, How Changing Prudence and Risk Aversion Affect Optimal Saving, October 2008 
2439 Erich Battistin, Clara Graziano and Bruno Parigi, Connections and Performance in Bankers' Turnover: Better Wed over the Mixen than over the Moor, October 2008

2440 Erkki Koskela and Panu Poutvaara, Flexible Outsourcing and the Impacts of Labour Taxation in European Welfare States, October 2008

2441 Marcelo Resende, Concentration and Market Size: Lower Bound Estimates for the Brazilian Industry, October 2008

2442 Giandomenico Piluso and Roberto Ricciuti, Fiscal Policy and the Banking System in Italy. Have Taxes, Public Spending and Banks been Procyclical in the Long-Run? October 2008

2443 Bruno S. Frey and Katja Rost, Do Rankings Reflect Research Quality?, October 2008

2444 Guglielmo Maria Caporale, Antoaneta Serguieva and Hao Wu, Financial Contagion: Evolutionary Optimisation of a Multinational Agent-Based Model, October 2008

2445 Valentina Bosetti, Carlo Carraro and Massimo Tavoni, Delayed Participation of Developing Countries to Climate Agreements: Should Action in the EU and US be Postponed?, October 2008

2446 Alexander Kovalenkov and Xavier Vives, Competitive Rational Expectations Equilibria without Apology, November 2008

2447 Thiess Buettner and Fédéric Holm-Hadulla, Cities in Fiscal Equalization, November 2008

2448 Harry H. Kelejian and Ingmar R. Prucha, Specification and Estimation of Spatial Autoregressive Models with Autoregressive and Heteroskedastic Disturbances, November 2008

2449 Jan Bouckaert, Hans Degryse and Thomas Provoost, Enhancing Market Power by Reducing Switching Costs, November 2008

2450 Frank Heinemann, Escaping from a Combination of Liquidity Trap and Credit Crunch, November 2008

2451 Dan Anderberg, Optimal Policy and the Risk Properties of Human Capital Reconsidered, November 2008

2452 Christian Keuschnigg and Evelyn Ribi, Outsourcing, Unemployment and Welfare Policy, November 2008

2453 Bernd Theilen, Market Competition and Lower Tier Incentives, November 2008

2454 Ondřej Schneider, Voting in the European Union - Central Europe's Lost Voice, November 2008 
2455 Oliver Lorz and Gerald Willmann, Enlargement versus Deepening: The Trade-off Facing Economic Unions, November 2008

2456 Alfons J. Weichenrieder and Helen Windischbauer, Thin-Capitalization Rules and Company Responses, Experience from German Legislation, November 2008

2457 Andreas Knabe and Steffen Rätzel, Scarring or Scaring? The Psychological Impact of Past Unemployment and Future Unemployment Risk, November 2008

2458 John Whalley and Sean Walsh, Bringing the Copenhagen Global Climate Change Negotiations to Conclusion, November 2008

2459 Daniel Mejía, The War on Illegal Drugs in Producer and Consumer Countries: A Simple Analytical Framework, November 2008

2460 Carola Frydman, Learning from the Past: Trends in Executive Compensation over the Twentieth Century, November 2008

2461 Wolfgang Ochel, The Political Economy of Two-tier Reforms of Employment Protection in Europe, November 2008

2462 Peter Egger and Doina Maria Radulescu, The Influence of Labor Taxes on the Migration of Skilled Workers, November 2008

2463 Oliver Falck, Stephan Heblich and Stefan Kipar, The Extension of Clusters: Differencein-Differences Evidence from the Bavarian State-Wide Cluster Policy, November 2008

2464 Lei Yang and Keith E. Maskus, Intellectual Property Rights, Technology Transfer and Exports in Developing Countries, November 2008

2465 Claudia M. Buch, The Great Risk Shift? Income Volatility in an International Perspective, November 2008

2466 Walter H. Fisher and Ben J. Heijdra, Growth and the Ageing Joneses, November 2008

2467 Louis Eeckhoudt, Harris Schlesinger and Ilia Tsetlin, Apportioning of Risks via Stochastic Dominance, November 2008

2468 Elin Halvorsen and Thor O. Thoresen, Parents' Desire to Make Equal Inter Vivos Transfers, November 2008

2469 Anna Montén and Marcel Thum, Ageing Municipalities, Gerontocracy and Fiscal Competition, November 2008

2470 Volker Meier and Matthias Wrede, Reducing the Excess Burden of Subsidizing the Stork: Joint Taxation, Individual Taxation, and Family Splitting, November 2008 